\title{
Echo voltage reflected by turtle on various angles
}

\author{
Sunardi $^{\mathrm{a},{ }^{*}}$, Anton Yudhana ${ }^{\mathrm{a}}$, Azrul Mahfurdz ${ }^{\mathrm{b}}$, Sharipah Salwa Mohamed ${ }^{\mathrm{c}}$ \\ ${ }^{a}$ Department of Electrical Engineering, Universitas Ahmad Dahlan, Yogyakarta 55166 Yogyakarta, Indonesia \\ ${ }^{b}$ Department of Electrical Engineering, Polytechnic Sultan Haji Ahmad Shah, 25350 Kuantan, Malaysia \\ ${ }^{c}$ Faculty of Electrical \& Electronics Engineering, Universiti Malaysia Pahang, 26600 Pekan, Malaysia \\ *Email: sunardi@uad.ac.id
}

\begin{tabular}{ll} 
ARTICLE INFO & ABS TR ACT \\
\hline Article history: & This research proposes the acoustic measurement by using echo sounder for \\
Received 20 March 2015 & Green turtle (Chelonia mydas) detection of 1 year, 12 and 18 years. Various \\
Revised 29 March 2015 & positions or angles of turtles are head, tail, shell, lung, left and right side. \\
Accepted 31 March 2015 & MATLAB software is used to analyse the frequency and the response of the \\
& turtle as echo voltage and target strength parameters. Based on the \\
& experiment and analysis, the bigger size of the turtle give the higher echo \\
Keywords: & voltage and target strength. The target strength of turtle for lung and shell for \\
Echo sounder & all ages are $-26.52 \mathrm{~dB}$ and $-26.17 \mathrm{~dB}$ respectively. The value of target \\
Echo voltage & strength of turtles in this research is different with fish in our previous \\
Target strength & research $(-38$ to $-44 \mathrm{~dB}$ ). Therefore, for future research, the repellant system \\
Green turtle & based on differences of target strength the turtle and fish for avoids the turtle \\
Fish & trapping in the net can be implemented to protect the population of turtle \\
& from extinction.
\end{tabular}

Copyright () 2015 International Journal of Advances in Intelligent Informatics.

All rights reserved.

\section{Introduction}

The number of turtle landing decreased every year because of frequently trapped in fishing net. Fishing net is used by fisherman to catch fish, but it also affected the turtle trapped. Because of this problem, the identification of turtle and fish are needed. Development of alert system needed to detect and alert the turtle from approach at fishing net. If the turtle approach, it will identified and dispels by sound emitted. Meanwhile, if the fish identified the sound gave no effect to the fish and it can be caught.

Sea turtles are large, air-breathing reptiles that inhabit tropical and subtropical seas throughout the world. Their shells consist of an upper part (carapace) and a lower section (plastron) as shown in Fig. 1. Hard scales (or scutes) cover all but the leatherback, and the number and arrangement of these scutes can be used to determine the species. Sadly, the number of marine turtles in most places has plummeted and some populations are on the brink of extinction.

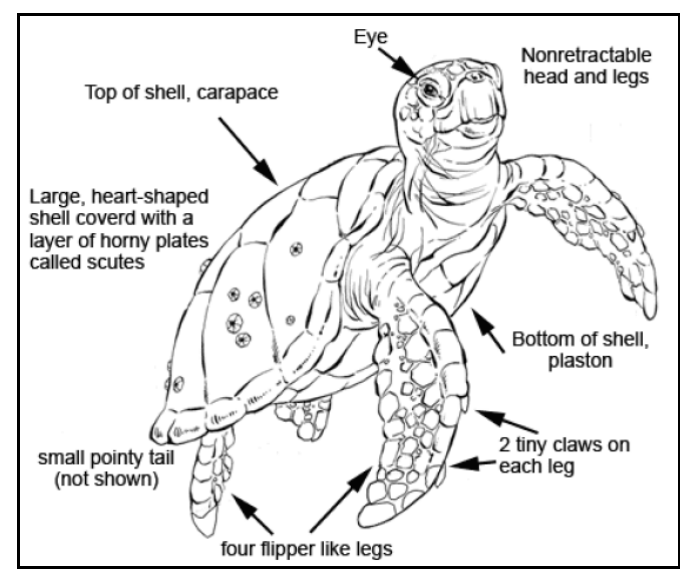

Fig. 1. Turtle [1] 
Over the last few centuries, sea turtle populations have decline dramatically due to various activities such as shore development, oil exploration, commercial fishing, marine recreation and pollution [2]. Fisheries activities have been contributed to be a major factor of death for juvenile and adult sea turtles. Although there are method to avoids turtle from trapping in fisheries net such as gear modification, material, fishing method and prohibits any fishing activities using gill net, but this method seems not affectively. Moreover, the caught of fish become plenty as usual.

This research is to detect the sea turtle 1 year, 12 and 18 years using sound technique. All of the turtles are in same species which is Green turtle (Chelonia mydas). Commercial echo-sounder is used to identify the echo voltage and target strength for turtle. The study will conduct as ex situ method which is in a water tank with sea water.

\section{Echo Voltage and Target Strength}

Sonar techniques, especially echo sounders, have been used since the beginning of the $20^{\text {th }}$ century for the detection of fish at sea by professional fishermen and fishery oceanographers [3]. A scientific echo sounder or also known as scientific sonar is a device used sonar technology for the measurement of underwater physical and biological components. Applications include bathymetry, substrate classification, studies of aquatic vegetation, fish, and plankton, and differentiation of water masses. Sonar is well known as Sound Navigation and Ranging system which is the technique that had many similarities to radar and electro-optical systems which using sound propagation to communicate or navigate with detected objects on or under the surface of water.

In fisheries technology, echo sounder is used as the sonar device. The device is widely used to observe marine animal. This device has proven to be a suitable and perfect tool in studying the spatial and temporal distribution of fish. In addition, echo sounder have operates at ten to hundreds kilohertz frequency [4]. For this experiment, $200 \mathrm{kHz}$ echo sounder was used.

Generally, target strength (TS) is refers to the ability of a target to return an echo and it is widely uses a sonar for active acoustic measurement applications. The acoustic scattering properties of the target are defined by the target strength [5]. Acoustic is the most effective tool for monitoring object under surface of water because of the ability of the sound to propagate long distance in the water. Acoustic scattering by spherical objects has been investigated by Rayleigh [6].

In sonar equation, target strength is defined as 10 times the logarithm to the base 10 of the ratio of the intensity of the sound returned by a target at a various distance. In this study, the target strength of object is measure using echo sounder which is used to transmit the acoustic pulse that emit by a transducer [7]. The transducer emits an acoustic pulse and it will return back the signals to be recorded and then the output signal is analyze using software such as MATLAB.

Size and reflectivity of sound are combined into a parameter called the backscattering cross section $\left(\sigma_{\mathrm{bs}}\right)$, which is essentially the acoustic size of the object. The backscattering cross section can be expressed as the amount of reflected sound intensity measured one meter away from the target, relative to the amount of energy incident upon the target. This parameter usually expressed in logarithmic then called the TS and expressed in $\mathrm{dB}[8]$.

Echo sounder is widely used in submarine navigation, fisheries technology and under water object classification. Echo sounder is use to catch fish for fisheries technology. Every type of fish will have different target strength. Information on the size of the recorded fish can be obtained from knowledge of target strength which may be found by analysis of the received echo signals [9].

There are basically two types of echo sunder which is scientific and commercial. In this study, the focus is uses on commercial echo sounder. The output signal of signal is tapped from circuit and then to be analysis. This signal is transmit from the transducer, then the high speed analog input USB converted the signal and transfer it to the laptop or computer for target strength identication. The target strength calculation is based on Urick formula which is TS $=10 \log \left(\mathrm{a}^{2} / 4\right)$ [10]. Urick's principle which is Principles of Underwater Sound gives the formula to calculate the TS for many other shaped objects [11]. The TS is one of the ingredients of the sonar equation for active acoustic detection applications [12]. Target strength is the acoustic size of a target in form of decibels (dB). The TS measurement suggested using echo signal observation from the transducer output [13]. 
Solid sphere is use in this study as a reference target or object because of the sphere echo voltage measurement is the best method in calculating target strength. Besides that, the echo characteristic of the object can be observed easily. The aim of this experiment is to obtain envelope echo signal structure of the sphere.

TS measurement using commercial echo sounder is one challenging method in studying the underwater living (animal). There is a technique that can apply in echo sounder calibration which is using an object whose acoustic properties are known. So that, sphere have been used as calibration and reference target in sonar equation and the sphere which is steel ball. Although the TS value of object are known, but it is important that the theoretical predictions should be tested by an experiment. Sphere echo voltage measurement is mostly used in calculating target strength so that the echo can be observed. The target strength for the object is measured and it depends on shape, size, and material properties. The object is place fix and not moving while the transducer was positioned in various distances from the target.

Commercial echo-sounder is the main device use for this experiment. The echo sounder was modified, so that, the signal is taken and tapped from the circuit before display on the screen. Table 1 shows the echo sounder setting. Echo sounder has been built with two frequency value which is 50 $\mathrm{kHz}$ and $200 \mathrm{kHz}$. In this research we use $200 \mathrm{kHz}$. There are three echo threshold levels which are red, orange and yellow.

Table 1. Echo Sounder Setting

\begin{tabular}{cc}
\hline Parameter & Value \\
\hline Frequency & $50 \mathrm{kHz} / 200 \mathrm{kHz}$ \\
\hline Echo Threshold Level & 3 Levels (Red, Orange, Yellow) \\
\hline Echogram Feed Rate (PF) & 4 \\
\hline Sensitivity Time Control (STC) & $45 \mathrm{~dB}$ \\
\hline Gain & High \\
\hline Noise Reduction Level (NR) & $5 \mathrm{~dB}$ \\
\hline Echo Dynamic Range (D. RNG) & $1500 \mathrm{~m} / \mathrm{s}$ \\
\hline Sound Speed
\end{tabular}

A transducer is a device that converts a signal in one form to another form of energy. The term transducer commonly implies the use of a sensor or detector. Transducers are used in this study to emit an acoustic pulse.

High Speed Analog Input USB is required to transfer the signal from the echo sounder to the laptop or PC. The port used is AI01 and GND. Software tracer DAQ ${ }^{\circledR}$ software included for acquiring and displaying data and generating signals, supported by MATLAB ${ }^{\circledR}$ Data Acquisition Toolbox ${ }^{\mathrm{TM}}$. The DC power supply was used to power circuits or boards that do not have their own power supplies. In this way it is possible to run up, test and develop a variety of circuits under the required conditions.

\section{Experimental Framework}

The whole experiment conducted uses turtles in large tank as shown in Fig. 2 filled with sea water. The dimension of water tank is 13 meter length, 5 meter height and 3 meter width. The holder was created by using woods to hold the transducer so that the transducer not sinks into the water. The width of holder is 2.8 meter and the height is 5 meter. 


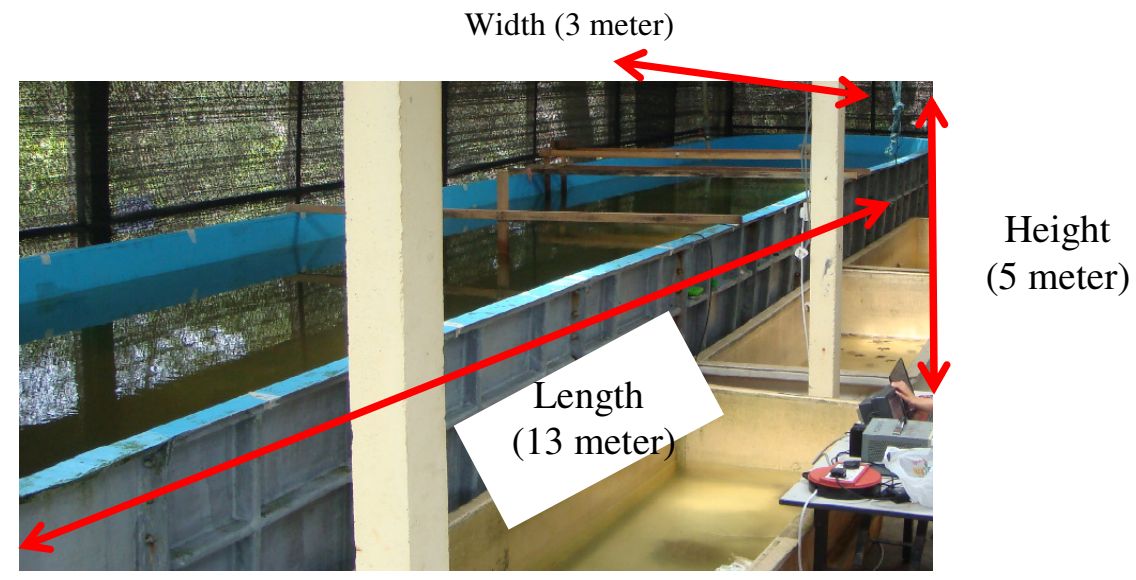

Fig. 2. Experiment Tank

This experiment is required to run MATLAB software with operating system of laptop is Windows 7 processor Intel Core i3 @ $3.40 \mathrm{GHz}$. Data collected from the experiment was analyzed and the signal then transformed from time domain to frequency domain. This program also require for the calculation of echo voltage. This software also used to build GUI system for turtle and fish detection. Experiment setup of the system is shown in Fig. 3.

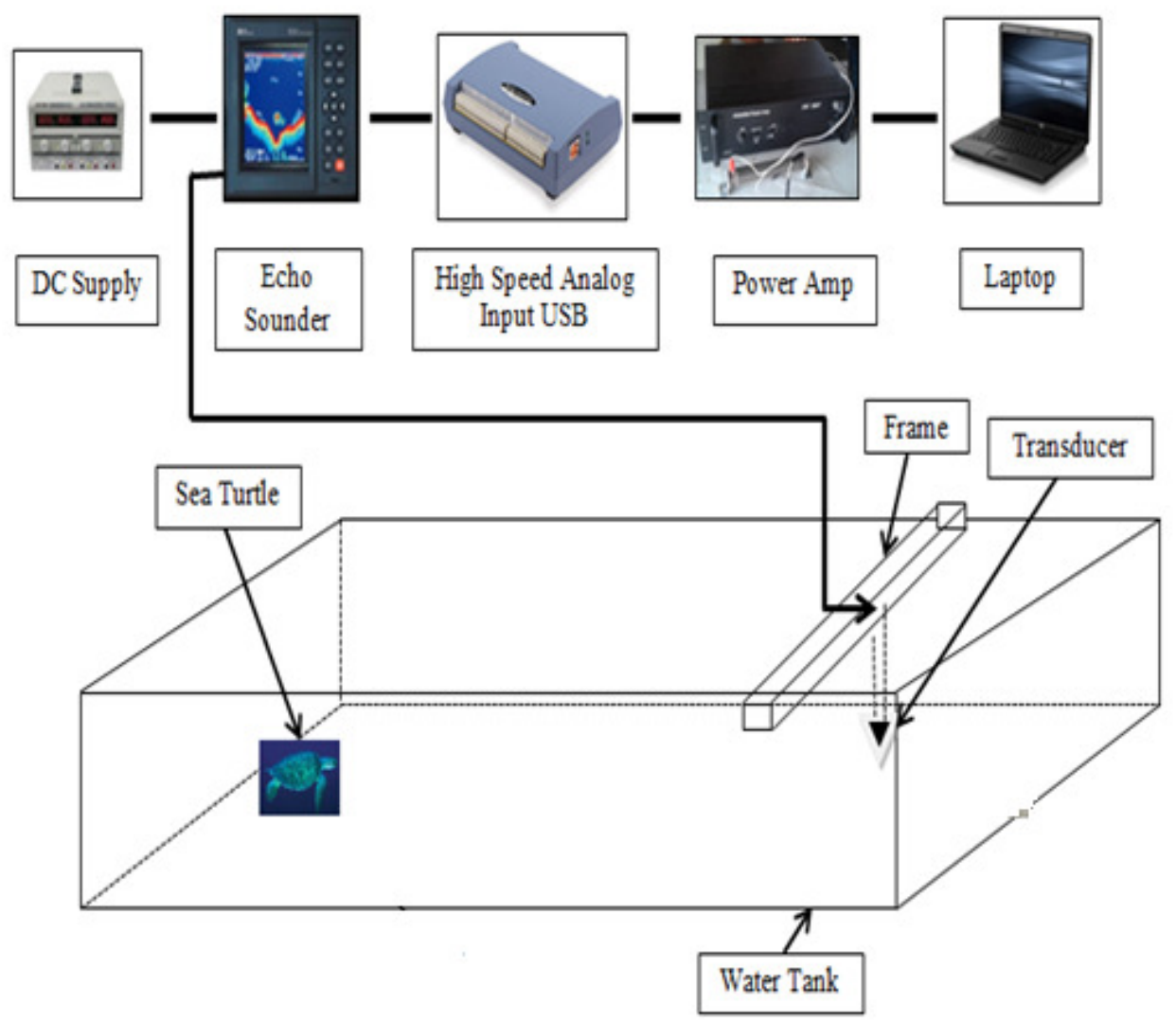

Fig. 3. Setup of the Experiment

There are three turtles that use in this project which are 1 year, 12 and 18 years. The characteristics of turtles used shown in Table 2. There are six sides of position or angle measurement for the turtle which are head, tail, left side, right side, tail and lung. 
Table 2. Characteristics of turtles

\begin{tabular}{cccc}
\hline Turtles & Age & Weight & Shell Length $(\mathbf{c m})$ \\
\hline 1 & 18 year & $29 \mathrm{~kg}$ & $61 \mathrm{~cm} \mathrm{\times} 56 \mathrm{~cm}$ \\
\hline 2 & 12 year & $25 \mathrm{~kg}$ & $58.5 \mathrm{~cm} \times 51 \mathrm{~cm}$ \\
\hline 3 & 1 year & $1.5 \mathrm{~kg}$ & $25 \mathrm{~cm} \mathrm{\times} 23 \mathrm{~cm}$ \\
\hline
\end{tabular}

Sphere is used as a reference target for the calibration purposes of acoustic scattering of object underwater. Sphere of solid steel ball $4.5 \mathrm{~cm}$ diameter is chosen based on the size and the material properties of object.

This research uses a standard target needed whose acoustic scattering properties are known. The echo sounder type JMC V1082 model is using to transmit the signal and transducer (radar sonic) act as generate and emit the acoustic pulse. At the beginning of the project, one program has been created to record all the data. By using MATLAB software, the program is needed during the experiment.

\section{Result and Discussion}

The analyzing of data presents the echo strength in term of voltage value of signal representation. Hence the value of TS can be calculated. The solid sphere (steel ball) is use as reference target so that the value of target strength require data from reference target to be solve in equation that have been made by Urick [14]. For this experiment, data was analyzed to calculate the echo voltage of object. There are three turtles used based on their ages which is 1 year, 12 and 18 years.

\section{A. Echo Voltage of Turtle}

There are five positions of turtle which is head, tail, shell, lung, left and right side. The result of the experiment using $200 \mathrm{kHz}$ echo sounder shown in Table 3 and Fig. 4 (turtle 1 year), Table 4 and Fig. 5 (turtle 12 years), and Table 5 and Fig. 6 (turtle 18 years). The voltage value is obtained from head, tail, shell, lung, left side and right side. All measurements recorded from 1 meter to 5 meter distance of transducer and object.

It obviously shows that echo voltage at lung or carapace for all ages of turtles and for all distances have highest value than other position. The second highest value of echo voltage for all ages and all distances is shell.

The envelope signals of turtle 1 year shows the reflected echoes were different for each angle measurement. The average echo amplitude of lung and shell are 7.63434 Volt and 7.49518 Volt respectively.

The envelope signals of turtle 12 years shows the reflected echoes were different for each angle measurement. The average echo amplitude of lung and shell are 9.66498 Volt and 9.68546 Volt respectively.

The envelope signals of turtle 18 years shows the reflected echoes were different for each angle measurement. The average echo amplitude of lung and shell are 16.86588 Volt and 15.80888 Volt respectively.

Table 3. Echo voltage of 1 year

\begin{tabular}{cccccc}
\hline \multirow{2}{*}{ Position } & \multicolumn{5}{c}{ Distance $(\mathbf{m})$} \\
\cline { 2 - 6 } & $\mathbf{1}$ & $\mathbf{2}$ & $\mathbf{3}$ & $\mathbf{4}$ & $\mathbf{5}$ \\
\hline Head & 2.6840 & 3.1694 & 3.2048 & 2.5953 & 2.7427 \\
\hline Tail & 3.0983 & 2.7070 & 3.3361 & 5.1957 & $\mathbf{1 0 . 7 3 0}$ \\
\hline Shell & $\mathbf{5 . 2 2 9 8}$ & $\mathbf{5 . 4 9 0 3}$ & $\mathbf{5 . 5 0 4 8}$ & $\mathbf{1 0 . 5 2 1 0}$ & $\mathbf{5 . 5 9 8 2}$ \\
\hline Lung & $\mathbf{5 . 4 7 3 6}$ & $\mathbf{7 . 7 5 4 1}$ & $\mathbf{1 5 . 6 0 0 6}$ & 2.8638 & 2.5638 \\
\hline Left & 3.4214 & 3.9762 & 2.0968 & 5.1792 & 4.4195 \\
\hline Right & 3.3307 & 3.1955 & 4.8385 &
\end{tabular}




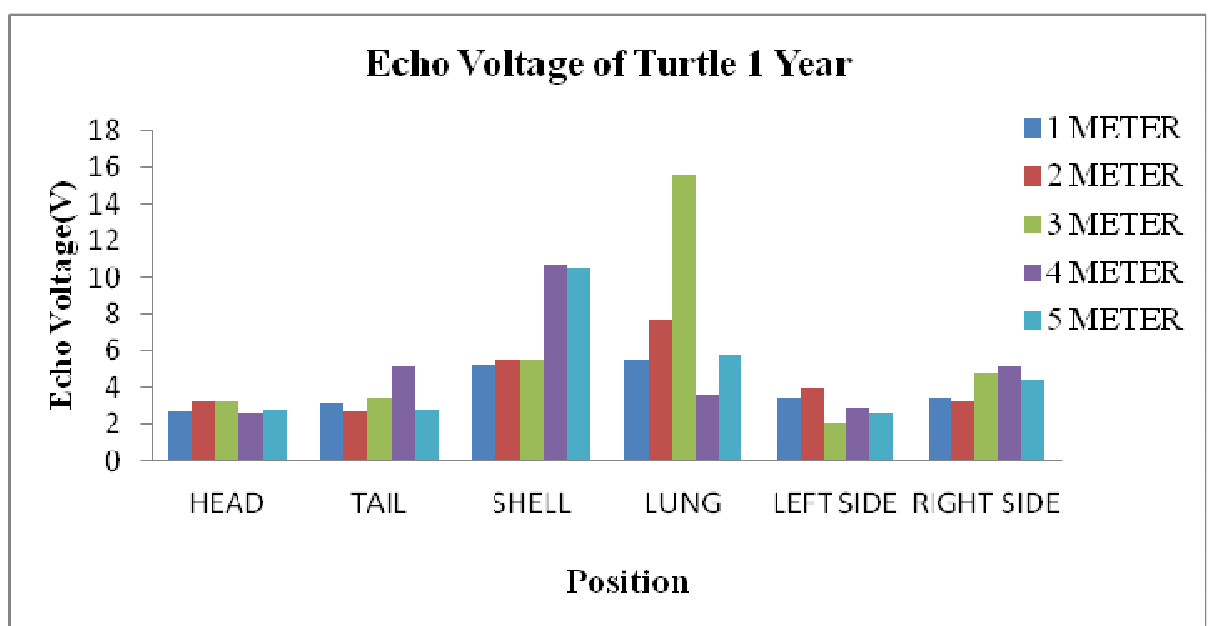

Fig. 4. Graph of echo voltage of turtle 1 year

Table 4. Echo voltage of 12 years

\begin{tabular}{cccccc}
\hline \multirow{2}{*}{ Position } & $\mathbf{5}$ & \multicolumn{5}{c}{ Distance $(\mathbf{m})$} \\
\cline { 2 - 6 } & $\mathbf{1}$ & $\mathbf{2}$ & $\mathbf{3}$ & $\mathbf{4}$ & $\mathbf{5}$ \\
\hline Head & 2.9124 & 3.4837 & 4.3801 & 3.0085 & 6.4587 \\
\hline Tail & 3.4473 & 4.0276 & 5.8685 & 3.4288 & 4.1937 \\
\hline Shell & $\mathbf{3 . 6 1 0 1}$ & $\mathbf{7 . 4 8 8 8}$ & $\mathbf{1 2 . 4 5 5 0}$ & $\mathbf{1 3 . 7 2 3 8}$ & $\mathbf{1 1 . 1 4 9 6}$ \\
\hline Lung & $\mathbf{3 . 9 5 4 0}$ & $\mathbf{7 . 9 1 7 8}$ & $\mathbf{8 . 7 7 4 7}$ & $\mathbf{1 4 . 5 1 3 3}$ & $\mathbf{1 3 . 1 6 5 1}$ \\
\hline Left & 2.9535 & 5.0727 & 6.0800 & 7.4270 & 12.5409 \\
\hline Right & 2.9104 & 4.1906 & 6.6467 & 6.4618 & 5.8657 \\
\hline
\end{tabular}

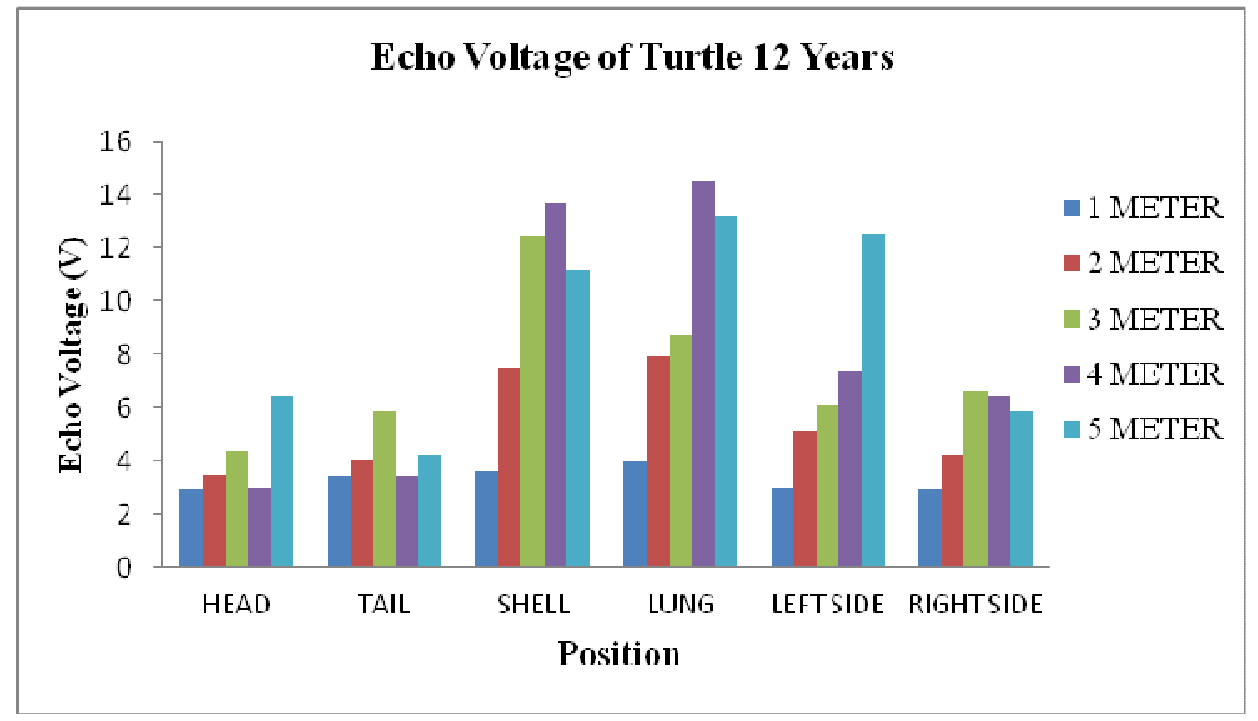

Fig. 5. Graph of echo voltage of turtle 12 years

Table 5. Echo voltage of 18 year turtle

\begin{tabular}{cccccc}
\hline \multirow{2}{*}{ Position } & \multicolumn{5}{c}{ Distance $(\mathbf{m})$} \\
\cline { 2 - 6 } & $\mathbf{1}$ & $\mathbf{2}$ & $\mathbf{3}$ & $\mathbf{4}$ & $\mathbf{5}$ \\
\hline Head & 4.5305 & 4.8656 & 6.9562 & 8.9421 & 6.3037 \\
\hline Tail & 4.2872 & 5.0468 & 7.4184 & 8.2747 & 7.4874 \\
\hline Shell & $\mathbf{4 . 7 4 4 2}$ & $\mathbf{8 . 4 9 6 5}$ & $\mathbf{1 9 . 0 0 6 2}$ & $\mathbf{2 4 . 8 6 8 8}$ & $\mathbf{2 1 . 9 2 8 7}$ \\
\hline Lung & $\mathbf{6 . 0 5 8 7}$ & $\mathbf{8 . 8 6 5 1}$ & $\mathbf{1 5 . 8 7 0 0}$ & $\mathbf{2 4 . 7 4 7 7}$ & $\mathbf{2 8 . 7 8 7 9}$ \\
\hline Left & 3.4106 & 5.1536 & 6.6458 & 7.9174 & 6.6353 \\
\hline Right & 3.3644 & 4.3644 & 6.1760 & 6.9350 & 4.7799 \\
\hline
\end{tabular}




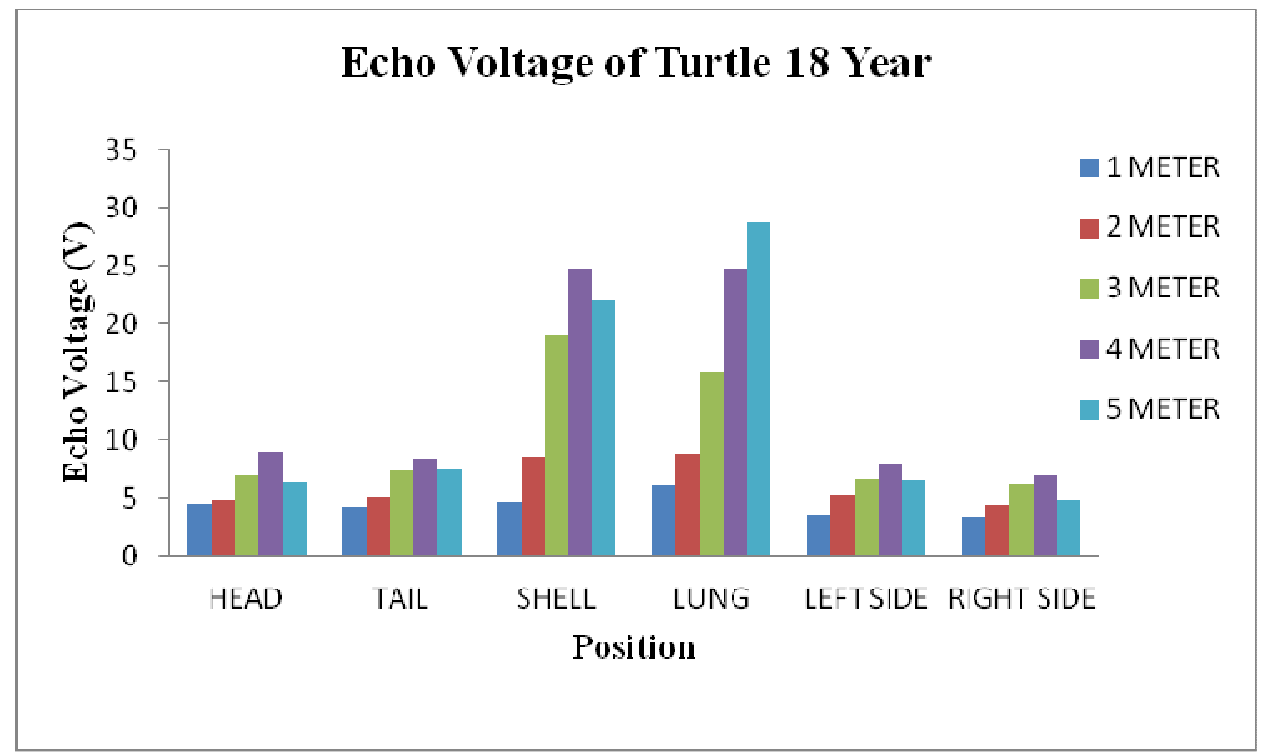

Fig. 6. Graph of echo voltage of turtle 18 years

\section{B. Target Strength of Turtle}

Solid steel ball size $4.3 \mathrm{~cm}$ used for this experiment. The echo voltage value is obtained from 1 meter to 5 meter distance. Table 6 represents the sphere (steel ball) as reference target echo voltage. This value used for calculated the target strength of turtle using formula of TS $=[10 \mathrm{log}$ $\left.\left(\mathrm{V}_{\text {object }}^{2} / \mathrm{V}_{\text {steelball }}^{2}\right)\right]+\mathrm{TS}_{\text {steelball }}$

The target strength of solid steel ball is $-39.372 \mathrm{~dB}$. This value used to calculate the target strength of turtle. Table 7 and Fig. 7 are represents the target strength value of turtle 1 year, 12 and 18 years. The target strength value is obtained from head, tail, shell, lung, left side and right side. The increasing of ages of turtle as the bigger its size will give the higher target strength value of turtle.

Table 6. Echo voltage of steel ball using $200 \mathrm{kHz}$ echo sounder

\begin{tabular}{cc}
\hline Distance $(\mathbf{m})$ & Voltage $(\mathbf{V})$ \\
\hline $\mathbf{1}$ & 5.4747 \\
\hline $\mathbf{2}$ & 4.5950 \\
\hline $\mathbf{3}$ & 1.4510 \\
\hline $\mathbf{4}$ & 1.2056 \\
\hline $\mathbf{5}$ & 0.7810 \\
\hline
\end{tabular}

Table 7. Target strength of turtle

\begin{tabular}{cccc}
\hline & \multicolumn{3}{c}{ Target Strength of Turtle (dB) } \\
\cline { 2 - 4 } Position & $\mathbf{1}$ Year & 12 Years & 18 Years \\
\hline Head & -36.3650 & -33.7644 & -29.7699 \\
\hline Tail & -33.3694 & -33.3358 & -31.2348 \\
\hline Shell & $\mathbf{- 2 8 . 5 1 0 2}$ & $\mathbf{- 2 6 . 6 6 8 6}$ & $\mathbf{- 2 3 . 0 3 2 8}$ \\
\hline Lung & $\mathbf{- 2 8 . 9 7 1 3}$ & $\mathbf{- 2 6 . 6 3 6 4}$ & $\mathbf{- 2 3 . 9 4 7 9}$ \\
\hline Left & -36.2324 & -29.8021 & -30.3649 \\
\hline Right & -33.2310 & -31.5666 & -31.6046 \\
\hline
\end{tabular}




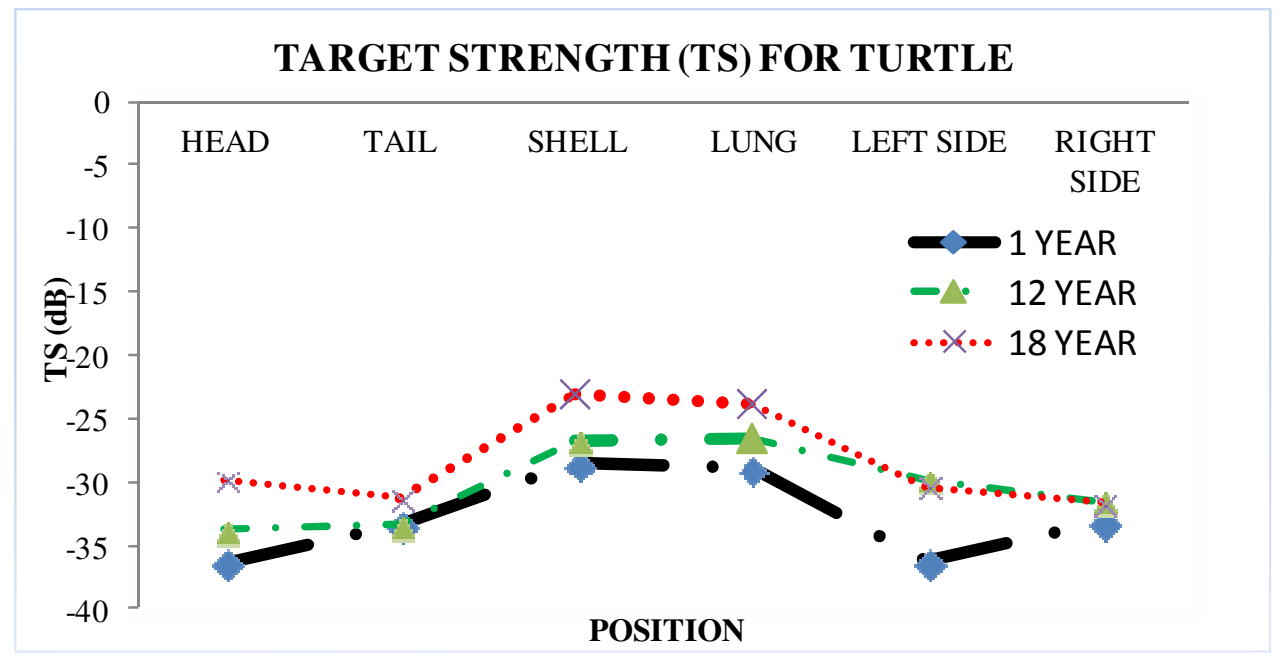

Fig. 7.

Graph of TS value for turtle

Based on theory, the target strength of object is depends on size of object. Sizes of object will effects to the value of target strength. It means that the values of target strength become higher as the size of object increases. From the calculation the echo voltage of object, the values suppose decrease as the target or object is place in increasing distance.

The whole result of object using $200 \mathrm{kHz}$ has the same pattern. The whole result of turtle looks like follow the theoretical. Based on the result, echo voltage of each object decreases as the distance is increase. There is some value did not correct due to mistakes in record the signal. Based on the result, the highest values are recorded at lung and shell positions for turtle.

Target strength of turtle, from the result, we can determine which position of turtle has the higher value means that the object absolutely effective in reflect the acoustic pulse. So the hardness of the object which is lung and shell has highest target strength. From the graph on Fig. 7, we can see that the target strength of turtle for lung and shell for all ages are $-26.52 \mathrm{~dB}$ and $-26.17 \mathrm{~dB}$ respectively.

Based on our research, the target strength of turtles are different with fish which are $-38 \mathrm{~dB}$ to $44 \mathrm{~dB}$ from our past research as shown in [8]. Therefore, for future research, the repellant system based on target strength differences of turtle and fish for avoiding the turtle trapping in the net can be implemented.

\section{v. Conclusion}

The target strength of turtle was calculated by using the formula while the echo voltage is obtained from the MATLAB program. We can conclude that an effect of the bigger size of turtle is higher value of voltage and target strength. Based on the analysis has been conducted, the target strength of turtle for lung and shell for all ages are $-26.52 \mathrm{~dB}$ and $-26.17 \mathrm{~dB}$ respectively.

The object and transducer must be place horizontal to each other so that the transducer will emit pulse directly to the object and the object can transmit back the pulse precisely. The settings of echo sounder also become one of the factors that make the error occur. The signal beam for $200 \mathrm{kHz}$ frequency is only $10^{\circ}$, therefore the analyzing of data, the signal appears is too small. Hence it will affect the calculation of echo voltage. A part from using sound to detected turtle or fish, for more accurately in future research, underwater camera will be used as additional input to differentiate the shape of turtle or fish. 


\section{References}

[1] Sunardi, J. Din, A. Mohd, R.B.R. Hassan, Nadzri Seman, Target Strength Measurement of Selar boops (Oxeye scad) Using $38 \mathrm{kHz}$ and $120 \mathrm{kHz}$, Asia-Pacific Conference on Applied Electromagnetics (APACE), Melaka-Malaysia, 4-6 December 2007,

[2] A. Mahfurdz, Sunardi, H. Ahmad, S.A.S.A Kadir, N. Sulong. Acoustic Strength of Green Turtle and Fish based on FFT Analysis. International Journal of Advanced Computer Science and Applications (IJACSA). Vol. 4, No. 9, October 2013, New York, USA.

[3] Sunardi, A. Yudhana, J. Din, Color Components Identification on Echogram, International Journal of Science and Advanced Technology (ISSN 2221-8386. Volume 3 No 6 June 2013

[4] D N MacLennan; Target Strength Measurements on Metal Spheres, Marine Laboratory, Aberdeen, 1982

[5] Jean-Pierre Sessareg, P. Cristini, N. Grigorieva, G. Fridman, Measurements and Modeling of Acoustic Scattering by a Spherical Elastic Shell Near an Interface, Department of Applied Mathematics and Mathematical Modeling, St. Petersburg State Marine Technical University, Russia

[6] Herbert Uberall, Acoustic scattering from elastic cylinders and spheres: surface waves (Watson transform) and transmitted waves, Department of Physics, Catholic University of America, USA

[7] S.M. Hasheminejad, N. Safari, Acoustic scattering from viscoelastically coated spheres and cylinders in viscous fluids, Department of Mechanical Engineering, Iran University of Science and Technology, Iran. December 2003

[8] Sunardi, A. Yudhana, J. Din, R.B.R Hassan, Fish Species Identification Based on its Acoustic Target Strength Using In Situ Measurement, International Journal of Aquaculture, Aquarium, Conservation \& Legislation (AACL), Nov 2010 (Vol. 3 No. 3)

[9] Keltron, Karakulam, Project Profile on Commercial Echo Sounder, Special Products Group P.O. Thiruvananthapuram, India.

[10] S.Anstee, Use of Spherical Objects as Calibrated Mine Hunting Sonar Targets, Maritime Operations Division Aeronautical and Maritime Research Laboratory

[11]L. Midttun, O. Nakken, On Acoustic Identification, Sizing and Abundance Estimation of Fish, Institute of Marine Research, Bergen.

[12] Mario Zampolli, Finn B. Jensen, Alessandra Tesei, Review of Target Strength of Cylindrical Objects for Waterside Security Applications, September 2008

[13] A. Mahfurdz, Sunardi, H. Ahmad, Sea Turtle Detection Based on Echo Signal Analysis, Malaysian Postgraduate Conference on Electrical, Electronic and Engineering Control Technology (MCEET). Pahang-Malaysia, 16-17 February 2012.

[14] Urick, R.J. 1983. Principles of underwater sound. 3rd ed. USA: McGraw-Hill. 